\title{
Charting the Future of Metropolitan Universities: The 2016 CUMU Annual Conference
}

\author{
Mary Ann Villarreal
}

At the height of pre-election anxieties and amid conversation among faculty and higher education administrators about how post-election policies would impact the efforts of higher education, the 2016 Coalition of Urban and Metropolitan Universities (CUMU) held its annual meeting in Washington DC. Focused, as always, on higher education and community engagement, the 2016 conference gave particular emphasis to future needs and issues. These conversations are especially critical now, as urban and metropolitan institutions, regardless of type or size, increasingly face new social justice challenges both on their campus and in their local communities. These societal and structural disparities range from access to services due to rising costs of living to the impact of the national tone of racial and citizenship inequities that continue to deeply divide our nation.

The conference theme "Charting the Future of Metropolitan Universities" brought together urban and metropolitan institutions committed to community partnerships and student success through forward building and forward looking initiatives. One of those partnerships honors the legendary work of Ernest A. Lynton, with the annual Earnest A. Lynton Award for the Scholarship of Engagement for Early Career Faculty. The 2016 recipient, Mara Tieken, Ed.D, assistant professor and the associate chair of education at Bates College writes in her essay, "The Evolution of a Community-Engaged Scholar" gives insight on her path from a rural teacher to a tenure-track position at an institution and her responsibility to continue to support others on a similar trajectory. Equally important, Tieken, brings to the forefront the importance of bringing rural communities into framework of community engagement, especially for institutions of higher education that have the resources to be good partners in developing policy.

The call for papers for the annual conference issue attracted a diverse selection of manuscripts outlining promising practices, presenting successful case studies, and existing opportunities to cement the foundation of anchor institutions in their local communities. Guided by the vision of the organization to strengthen "institutions that are developing new responses to the pressing educational, economic, and social issues of the day," the manuscripts in this issue represent all those areas.(Retrieved from http://www.cumuonline.org/). The topic placed innovation and strategic initiatives at the heart of the conversation. Whatever institutional anxieties may have existed about the future of higher education at the turn of the election, the underlying message of the manuscripts revealed deep institutional commitments to serving communities.

In his opening remarks at CUMU, Dr. Blair Ruble, Vice President for Programs at the Woodrow Wilson Center, Ruble asks "What does it mean for a city to be a place of promise?" We are reminded by Ruble that this question is multi-layered when we overlay cities on regions and universities on cities. While the national politic focuses on threats of terrorism and acts of war, 
urban campuses must not only remain vigilant to be a part of the national conversation, they must also ensure that their local and regional partnerships are built with purpose. Ruble provides the United Nations New Urban agenda as a compass for universities to consider: "inclusive cities, safer cities, governance, economic development." Embedded in this issue are ongoing commitments to addressing many of those issues, such as the challenges that low-income communities face with housing, ongoing segregation of communities of color, and the continual polarizing demands of accountability without adequate resources.

\section{In This Issue}

For several of the authors, this conference issue offered the opportunity to explore contemporary challenges. For instance, unable to ignore the fast paced increases in the cost of housing and the attention drawn by policy makers to address housing affordability and homelessness, Judith A. Ramaley, provides a detailed exploration of the demand and challenges that are inherent in Portland's housing crisis. Significant to her work is the groundwork she offers for the bigger issue that urban and metropolitan higher education institutions must confront: the changing nature of institutional community service and civic responsibility. Building on the scholarship of Danah Boyd, Ramaley squarely captures the most significant questions that CUMU institutions must ask themselves, "How do we stay relevant?" and "How do we change the way we collaborate?" Ramaley argues that we must not only think and act differently, we must understand the problems from a diverse set of perspectives.

Along with housing challenges, communities face food insecurities in urban areas where developing models of sustainable action may not be apparent. Michael R. Schläppi, professor of biology at Marquette University, shares detailed description of the development of the Cooperative of the Inititute of Urban Agriculture and Nutrituion (CIUAN) serves a platform for integrating interdisciplinary undergraduate research opporotunities that address "potential for community development and revitalization." In his case study the result is an innovative practice that produces more than just rice, but a recipe to "pursue excellence for human well-being. Staying within the Jesuit mission, Desiree Zequero and Erin Doran also reflect on the complexity of the challenges imposed by competing demands imbedded in the Urban-Serving Research University Mission: How to best serve and utilize shared cross-institutional resources or developing consortium with like needs is key to creating an environment for successful faculty retention, lowing costs for student access, and increasing student completion.

Faced with two realities, the call by the Colorado Master Plan for Higher Education to increase the number of college credentials by 1000, and the second largest attainment gap in the nation, Metropolitan State University of Denver had a daunting task. Mark Potter details the work of a cross-divisional team to create a data driven action plan to increase support and success at MSU Denver.

For several campuses, campus centers have proven crucial to efforts aimed at linking campus and community. Institutions seeking promising practices for creating a successful institutional- 
wide center for community engagement are familiar with the University of Nebraska at Omaha (UNO) Barbara Weiz Community Engagement Center. The authors Anthony Starke, Keristiena Shenouda, and Deborah Smith-Howell provide a detailed methodology to assess and measure the work of the center. The framework offered not only allows for institutional flexibility in defining terms, the authors provide recommendations for consideration that include creating a reciprocal relationship rather than a one-way design.

The nation has suffered greatly for ignoring the economic, social, and political disenfranchisement of people of color, especially that of African Americans, a reality that emerges poignantly across many urban campuses. When in the public eye and faced with the reality of the Baltimore Uprising and murder of Freddie Grey, universities must stay steady and build bridges for those left in the storm. At Townson University, Samuel Collins, Matthew Durington and Nicole Fabrant, demonstrate the effectiveness of collaboration among faculty from three academic departments reflected on their responsibility to engage in a pedagogy that invited students and community groups. While the course allowed both audiences to reimagine the relationship between the institution and the community, the outcomes provided a basis for curricular reform with a focus on social justice.

The racial crisis of Baltimore is compounded by the economic depression of the region as evidenced by Ronald Williams and Elgin Klugh at Coppin State University. Their study frames the beginning of the development of The Center for Strategic Ingrepreneurialship. Building upon the evidence of impact that Black owned business have on the outlook of youth, the authors lay out a strangely named innovative design to bring multiple partners to the conversation on revitalization. Where Ramaley began the conversation in the need to remain relevant or by conference guidelines "What are you doing right?" the issues ends on the pieces still unfinished or "What keeps you up at night?" William and Klugh connect the ends with a novel socially responsible extension from a HBCU to the heart of the community in which it exists. 


\section{Author Information}

Mary Ann Villarreal serves as assistant vice president of strategic initiatives at California State University, Fullerton, the third largest university in the state, serving more than 40,000 students, the majority of whom are the first in their family to pursue a college degree. She designs and launches multiple projects, providing her the opportunity to build working relationships across the university. She works across the university's nine colleges and six divisions to ensure all students have equitable access to both academic success and the path to upward mobility that comes with it.

Mary Ann Villarreal, Ph.D.

Assistant Vice President, Strategic Initiatives

Office of the Provost

California State University, Fullerton

2600 Nutwood Ave., Ste. 1060

Fullerton, CA 92831 